\title{
A theory of the US innovation ecosystem: Evolution and the social value of diversity
}

\author{
Ashish Arora* $^{*} \quad$ Sharon Belenzon ${ }^{\dagger} \quad$ Andrea Patacconi $^{\ddagger}$
}

May 14, 2018

\begin{abstract}
This paper reviews evidence on the changing structure of the US innovation ecosystem and then develops a simple model of the rise and fall of the large corporate lab. We suggest that the growth of American universities allowed at first the formation of large corporate labs by training scientists to work in industrial labs. Subsequently, however, start-up invention spurred by university research provided an increasingly attractive alternative to internal research, leading to the demise of the large corporate lab. We use this model to assess whether the substitution of corporate research with start-up invention can result in insufficient variety in the innovation ecosystem. We find that, when levels of university research and start-up activity are high, large firms can have socially excessive incentives to focus on 'open innovation'. Thus, despite its potential efficiency benefits, a division of innovative labor may encourage 'me too' innovations and reduce diversity in the innovation ecosystem.
\end{abstract}

Keywords: innovation ecosystems, scientific research, diversity in organizational forms and R\&D.

JEL Classification: O31, O32, O16.

\footnotetext{
*Fuqua School of Business, Duke University, and NBER. Email: ashish.arora@duke.edu

${ }^{\dagger}$ Fuqua School of Business, Duke University, and NBER. Email: sharon.belenzon@duke.edu

${ }^{\ddagger}$ Norwich Business School, University of East Anglia. Email: A.Patacconi@uea.ac.uk
} 
Science is, surely, a very practical activity but, typically, only in the long-run (Rosenberg, 1991: 337).

\section{Introduction}

This paper brings together three themes that featured prominently in Nathan Rosenberg's research: (i) The economic importance of science (e.g., Rosenberg, 1974, 1990; Rosenberg and Nelson, 1994) (ii) the idea that technological advance proceeds through the interactions of many actors in an innovation system (e.g., Mowery and Rosenberg, 1993, 1998; Nelson and Rosenberg 1996), and (iii) that diversity and experimentation are very important to the process of technical change and economic growth (e.g., Rosenberg and Birdzell, 1986; Rosenberg, 1992).

In a paper provocatively titled "Why do firms do basic research (with their own money)?" Rosenberg (1990) focused on the apparently anomalous phenomenon of corporate research. Somewhat ironically, corporate research had already in decline from its zenith in the 1980s (e.g., Coombs and Georghiou, 2002; Mowery, 2009, Arora, Belenzon and Patacconi, 2018). University spin-offs and other start-ups, often funded by venture capital, were emerging as important innovators (e.g., Drake, 2014). The Bayh-Dole Act of 1980 has also encouraged universities to patent and licence their technologies, contributing to entrepreneurial dynamism in the US. Mowery (2009: 1) argues, and we agree, that in many ways these developments have not create an entirely new system, but rather "revived important elements of the industrial research "system" of the United States in the late 19th and early 20th centuries", where large corporations mainly relied on small inventors and technology markets to provide growth opportunities.

In this paper, we follow Mowery and review the evidence on the changing structure of the US innovation ecosystem, including recent evidence that has since become available. We then propose a simple model that highlights linkages between university and industry research, and can capture the rise and fall of the large corporate lab. Large firms invent either through research carried out inside their labs or by partnering with start-ups (open innovation). Invention by start-ups is spurred by university research. ${ }^{1}$ We suggest that universities initially contributed to the growth of large corporate labs by training scientists that corporations could

\footnotetext{
${ }^{1}$ The model could equivalently be interpreted as one where large firms acquire start-ups and then refine and commercialize their inventions.
} 
hire. Over time, however, university research reduced the incentives to invest in corporate labs by providing an increasingly attractive alternative: start-up invention. Note that in our model technology markets provide most of large firms' inventions both early on and in later periods. The reason, however, is different. Early on technology markets are thin but setting up a large corporate lab is prohibitively costly due to lack of human capital. Later on hiring scientists becomes relatively cheap but technology markets become even more attractive.

We use this model to address a fundamental issue in the innovation literature: "whether markets, left to themselves, are likely to spawn a socially desirable degree of firm [and innovation] heterogeneity" (Holbrook, Cohen, Hounshell and Klepper, 2000: 1017). There are two types of heterogeneity in our model. First, large firms and start-ups may focus on different types of problems. For instance, large firms may work on improving the architectural aspects of a product, while start-ups may focus on improving specific components. We call this heterogeneity in types of inventions. Second, even though multiple start-ups can work on improving a single component (so that their inventions are substitutes), they may do so by pursuing different approaches. This heterogeneity in approaches also benefits society because it ensures that, even if one start-up fails, another may succeed.

We find that in some cases large firms over-invest in internal research and engage too little in open innovation (compared to what a social planner would do), and in other cases large firms under-invest in internal research and engage too much in open innovation.

Large firms tend to engage too little in open innovation because the rents from successful collaboration are shared with partners. As such, large firms tend to value collaboration too little compared to the social planner and tend to over-invest in internal research. Counterbalancing this effect, however, there are appropriability considerations, which may give large firms excessive incentives to engage in open innovation. These excessive incentives stems from the fact that a large firm still gains something from commercializing a start-up invention, even when other similar inventions are plentiful. There is a wedge between private and social returns from innovation, because firms care about winning market share (so that substitute, 'me too' inventions can be profitable as well), whereas society only cares that one of these inventions is brought to market. Because of this effect, open innovation can become an excessively attractive alternative to internal research, and large firms may under-invest in internal research. In this case, we have too little heterogeneity in types of inventions (too little internal innovation and too many similar start-up innovations), although the heterogeneity 
in approaches associated with start-up invention can in principle also benefit society.

The model suggests that over the last quarter of a century, the US economy may have transitioned from a situation where investments in internal research were excessive to a situation where internal research is now underfunded (from society's viewpoint). The growth of American universities has created a vibrant start-up ecosystem, but the risk of underinvestment in internal research is most salient precisely when start-up invention is plentiful. In that case, the open innovation strategy of large firms can result in innovations that the market would have generated anyway. Society would benefit if large firms invested more of their resources in internal research.

To maintain focus, our model neglects the considerable challenge of managing research in large, for-profit firms. These challenges include not only the potential agency conflicts between managers and investors, though these are considerable, but also the conflicts between the need to allow researchers to pursue speculative long-term projects and the incentives and culture of focusing on directly commercially relevant activities. Hounshell and Smith (1988), Kay (1988), and Hoskisson, Hitt and Hill (1993) provide useful discussions of these and other issues in the management of research.

\section{Evolution of the US innovation ecosystem: A histor- ical perspective}

Over the last 150 years, the United States rose from a relatively backward position in science and technology to a position of undisputed pre-eminence. In this section we summarize the development of the US scientific-industrial complex, which has been extensively described by, inter alia, Nelson and Rosenberg (1994, 1996), Hounshell (1996) and Mowery (2009). We supplement their accounts with more recent data, including evidence reported in Arora et al. (2018).

Our discussion focuses primarily on research, rather than development, and highlights the changing roles of three key actors in the US innovation ecosystem: universities and other public research institutions, such as the Federal labs and the National Institute of Health (henceforth, "universities" for short), large corporations and their corporate labs (henceforth, "large firms"), and (iii) individual inventors, small firms and science-based startups (henceforth, "small firms" or "start-ups"). We largely neglect the very important role of federal government in identifying strategic technology areas and promoting research and 
innovation in those areas. See, e.g., Mowery (2010), Mazzuccato (2013) and Klepper (2016, chapter 5) for more on this.

We higlight two key trends: the rapid growth of the American system of higher education, and the rise and fall of the large corporate lab. The rise of the large corporate lab also coincided with a decline in the importance of technology markets, while its fall was accompanied by a resurgence of these markets and by an increasing role of small firms in the US innovation ecosystem.

Following Mowery (2009), we divide our discussion into three periods: 1870-1940, 19401980, and 1980-to date. ${ }^{2}$

\subsection{0-1940: Early development of the US scientific-innovation complex}

American universities had, from the early days of the republic to the end of World War II, a widespread reputation for being oriented toward "practice and vocation" (Rosenberg and Nelson, 1996: 88). Colleges catered to the needs of the their communities by teaching subjects such as agriculture and home economics, while research and training also tended to reflect the demands of local industries. By the 1920s, the University of Akron, for instance, trained personnel for the local rubber industry and became well known for its research in the processing of rubber. The universities of Kentucky and North Carolina did extensive work on developing technologies for the tobacco industry (Rosenberg and Nelson, 1996). Scientists at the University of Oklahoma pioneered the use of reflection seismology for oil and gas exploration in the 1920's and to this day the University of Oklahoma boasts one of the leading petroleum engineering programs in the US. But despite these and other examples of excellence, it is fair to say that American universities lagged well behind their leading European counterparts in terms of research quality. Perhaps the most revealing indicator in this respect was the fact, noted by many observers, that most of America's leading scientists got their training in Europe.

To some extent, the close intertwining between universities and local communities was a consequence of limited federal funding, which increased universities' reliance on state and

\footnotetext{
${ }^{2}$ As in most long-term historical processes, identifying specific start and end dates for given periods is difficult. Mowery (2009), for instance, takes 1985 as the start date of the third period in the development of industrial R\&D in the US. We chose 1980 because (i) it is simpler to divide the whole period of analysis (1870-to date) in decades, and (ii) the Bayh-Dole Act and other important institutional developments took place in the early 1980s.
} 
industry funding. The connection was so strong that, according to some observers, a large share of American university research was essentially industrial problem solving, at least until the 1920's (Bruce 1987; Geiger, 2004). University-industry linkages were evident in the pharmaceutical sector, where companies such as Squibb, Eli Lilly, Merck and Upjohn supported many university research programs (Swann, 1988). In industries such as railroads, oil refining, and electrical lighting, firms relied upon independent inventors, but also tried to engage university scientists as consultants. After World War I, federal support for basic research grew but the commitment was less than complete, as exemplified by Hale, Millikan, and others' failed attempt to create a German-style, national scientific laboratory devoted to basic research (Hounshell, 1996).

Corporate investments in in-house laboratories were also initially quite modest. The leading American firms of the 1870s and 1880s, such as the railroad companies and Western Union, mostly relied on external inventions. However, during the 1870s, the leading railroad companies began employing college trained engineers to perform tests and gather data more systematically. Over time,they established industrial labs to evaluate the quality of these external inventions and other inputs (Usselman, 1991; Mowery, 1995; Hounshell, 1996; Carlson, 2013). For instance, the Pennsylvania Railroad's chemical laboratory in Altoona, established in 1876, focused on the standardization and testing of supplies such as steel rails and lubricating oils. Innovation, when it occurred, was incremental in nature. While Pennsylvania Railroad was quick in the adoption of many important innovations, these mostly came from independent inventors such as George Westinghouse (Usselman, 1984).

This division of innovative labor between large corporations, which focused on improvements and commercialization, and small firms and individual inventors, which focused on invention, was supported by an active market for technology, especially in the 1880-1920 period (Lamoreaux and Sokoloff, 1999). These markets for technology, however, did not remain vibrant for long. During the inter-war years, corporations grew larger and more anxious to control and "routinize" innovation. Their propensity to rely on external innovations decreased. Reasons are varied but include growing product-market competition, which made research a more important source of competitive advantage, anti-trust pressures, which reduced alternative sources of growth besides internal research, and the rising costs of invention, which made it difficult for inventors to continue to operate independently (Lamoreaux and Sokoloff, 1999; Hounshell, 1996). As a result, corporate investments in internal research grew 
rapidly. For instance, using National Research Council survey data, Mowery and Rosenberg (1998) show that employment of scientists and engineers in US manufacturing industries, steadily rose from less than 3,000 in 1921 to nearly 46,000 in 1946.

\subsection{0-1980: The age of Big Science.}

The victory in World War II was a watershed moment for American science. The victory was attributed at least in part to the ability of the US government to mobilize the US scientific community and channel a massive research effort to military and industrial purposes. The atomic bomb was without doubt the most prominent example of the power of science (for better or for worse), but developments such as the radar and the mass production of penicillin also played an important role. The result was a very significant improvement in the status of science and scientists among policymakers, managers, and the general public. The effect on the scale and organization of scientific activity were far-reaching.

Most notably, federal support for research and development in universities expanded very rapidly. Table 1, which updates Table 2 in Rosenberg and Nelson (1994) using more recent NSF data, shows that Federal support for academic R\&D grew more than sixfold in real terms during the decade 1955-1965. The same figure more than doubled from 1965 to 1975, and then again from 1975 to 1985. In the 1960's and 1970's, Federal support for academic R\&D as a percentage of total reached its peak.

A second significant change was the shift in the composition of academic R\&D towards the basic research end of the spectrum. While linkages between universities and industry remained strong in the US, the notion that universities' primary mission is to advance the frontiers of knowledge gained momentum. Table 2, which uses NSF data to update Table 4 in Rosenberg and Nelson (1994), shows that the percentage of basic research in total academic R\&D grew from 52\% in 1955, to $69 \%$ in 1960 and 76.5\% in 1965. By mid 1960's, American universities enjoyed a world leading status in most fields of science. Perhaps the best indicator

of this was the reversal of a previously noted pattern: students now flew from Europe to the US to do their graduate training (Rosenberg and Nelson, 1994).

\section{Tables 1 and 2 (Tables 2 and 4 in Rosenberg and Nelson 1994, updated)}

The growing practical applicability of recently discovered scientific principles, landmark inventions (e.g., vacuum tubes, radio, synthetic rubber, nylon), and the rapid increase in 
government funding in the United States also led to more companies investing in internal research after World War II. The earlier commercial successes of scientific discoveries by companies such as Du Pont and General Electric lent credibility to the idea that investments in research could be a source of competitive advantage. Evidence from the largest 200 US manufacturing firms indicates that, during the period preceding World War II (1921-1946), investments in R\&D tended to reinforce the position of dominant firms (Mowery, 1983). Corporations such as AT\&T, Merck, IBM and Xerox subscribed to the view that research was the key to growth. They employed thousands of scientists whose chief objective was to conduct research. At its peak in the late 1960's, AT\&T's Bell Labs employed 15,000 people, about 1,200 of which had PhDs (Gertner, 2013). To date, its alumni include 14 Nobel Prize winners and 5 recipients of the Turing Award. Innovations attributable to Bell Labs include the transistor, fiber optics, lasers, cellular telephony, the $\mathrm{C}$ programming language, and the Unix operating system.

\subsection{0-to date: Open innovation and the demise of the large corporate lab.}

The 1980's were characterized by important institutional developments. The Bayh-Dole Act of 1980, which permits academic institutions to own patents resulting from publicly funded science, encouraged American universities to become more engaged in the commercialization of their research. Various patent and administrative reforms, such as the creation in 1982 of a "pro-patent" Court of Appeals in the US, strengthened intellectual property rights, arguably promoting entrepreneurial activity and technology markets. The widely successful IPOs of venture-backed Genentech in 1980, 3Com in 1984, Sun Microsystems and Oracle in 1986, contributed to the growth of the venture capital industry in the US (Kenney, 2011), providing science-based start-ups with a new and potential valuable source of capital.

At about the same time, perceptions of the profitability of corporate research began to change. Success stories such as Du Pont's started to fade from memory. Xerox was taken as a more paradigmatic example, for its inability to profit from the many inventions that its Xerox's PARC Lab had generated. Books such as "Fumbling the Future: How Xerox Invented, then Ignored, the First Personal Computer" by Smith and Alexander (1988)

reinforced the view large firms were often bureaucratic and myopic, and their research would therefore mostly end up benefiting other firms, such as nimble and hungry start-ups. 
Corporate spending on research in the US began to decline as a share of total R\&D expenditure. Figure 1 shows that the share of basic and applied research in corporate R\&D in the US dropped from $28 \%$ in 1985 to less than $20 \%$ in 2015.

\section{Figure 1. Less R, More D, Inputs}

Focusing on public companies and using data on corporate publications in scientific journals as a measure of corporate research, Arora et al. (2018) also find a marked drop in corporate research in a wide range of industries (see Figures $2 \mathrm{a}$ and $2 \mathrm{~b}$ ). Further, they find that the drop reflects both a decline of research by established firms as well as the entry of many firms that perform little research, and that this decline is associated with a reduction of the private value of research.

\section{Figure 2a and 2b. Less R, More D, Publications}

Given that science remains useful to invention, the decline in corporate publications may reflect an increasing reliance on external knowledge by large corporations. Corporations may withdraw from research because a lot of useful research is already being produced by external institutions. Arora, Belenzon and Sheer (2017) show that the decline in corporate publications is related to a reduction in the use of internal research and an increase in the use of external science, as measured by citations to scientific publications by corporate patents. Figure 3 shows that patents by corporations cite less of their own published work, and more papers published by external institutions. External research and invention may in part be financed by large firms themselves, through university-industry collaborations, licensing and contracts, corporate venture capital investments, or outright acquisitions (e.g., Arora et al., 2001; Dushnitsky and Lenox, 2005). ${ }^{3}$ Thus, large firms may be withdrawing from internal research to concentrate on development, while absorbing external research from universities and start-ups.

\section{Figure 3. Corporate patents and internal research}

\footnotetext{
${ }^{3}$ Arora et al. (2016) find that a third of all externally sourced inventions are sourced through licensing, contracts, and outright acquisitions.
} 
The institutional developments of the early 1980's arguably created an ecosystem where research from universities and university-spawned start-ups is more abundant and 'packaged' in a way that it is easier for large firms to absorb. A variety of data reflects this claim (see Figure 4). American universities started filing for patents at an increasing rate, from about 5,000 patents in 1995 to more than 20,000 in 2015. Licensing income increased from less than $\$ 600$ million in 1995 to almost $\$ 2$ billion in 2015. The number of start-ups formed using university inventions more than quadrupled during the same period, from less than 200 in 1995 to more than 900 in 2015. Universities produced nearly $75 \%$ of the total scholarly output in 2013, up from $69 \%$ in 1999.

Stanford University provides an extreme example of the impact of university education

and research on the economy. Based on a large-scale survey of Stanford alumni and staff, Eesley and Miller (2018) estimate that nearly 40,000 companies can trace their roots to Stanford. These companies created an estimated 5.4 million jobs and generate annual world revenues of $\$ 2.7$ trillion. Eesley and Miller (2018: 130) calculate that, "[i]f these companies collectively formed an independent nation, its estimated economy would be the world's 10th largest".

\section{Figure 4: University patent applications, licensing and start-ups}

Among corporations, the contribution of large firms to research and innovation declined, and the contribution of small firms rose. NSF data indicate that firms with more than 10,000 employees accounted for 73 percent of non-federally funded R\&D in 1985. By 1998, this share had dropped to 54 percent, and to 51 percent by 2008 (Mowery, 2009). A different indicator of the decline in the relative importance of large firms is the sharp drop in share of large firms in the R\&D 100 awards winners: whereas 41 percent of the awards went to Fortune 500 firms in 1971, only 6 percent went to Fortune 500 firms in 2006 (Block and Keller, 2009).

An important class of small firms are venture-backed start-ups. VC partnerships finance a very small minority of all new firms - about $1 / 6$ of $1 \%$ on average per year in the US (Kaplan and Lerner, 2010; Lerner, 2012). Yet, VC-backed firms feature disproportionately among the fastest growing and the best performing companies. In the US from 1999 to 2009, over $60 \%$ of IPOs originating from industrial start-ups received VC funding. VC-backed firms are also distinctive innovators. Kortum and Lerner (2000) estimate that, on average, a dollar 
of venture capital results in three to four times more patents than a dollar of traditional corporate R\&D suggesting superior efficiency in invention, but also perhaps a greater focus on product, rather than process, invention by VC-backed startups.

Figure 5 examines whether VC-backed start-ups are making up for some of the deficit in publications created by large corporations. Our evidence suggests that the answer is in the negative. Rather than being independent sources of new science, venture-backed start-ups appear to focus on patenting and commercializing discoveries made elsewhere. Thus, their most important role may be as translators of university research, or as external paths to innovation of discoveries made within larger corporations (i.e., spin-offs).

\section{Figure 5: Publishing and patenting by US venture capital backed start-ups}

Overall, the evidence for the period 1980-2006 is consistent with a division of labor in which universities specialize in research, small start-ups convert promising new findings into inventions and larger, more established, firms specialize in product development and commercialization. In this view, smaller firms have a comparative advantage in experimenting and generating inventions, whereas larger firms have an advantage in exploiting them. Large firms may invest in scientific capability to be effective buyers of knowledge.

\section{A model of the US innovation ecosystem}

In this section, we develop a simple model of the US innovation ecosystem. We then use the model to examine how the incentives to invest in internal research may have changed over time and the welfare implications of these trends. In our model, inventions can be produced by large firms in their labs and by start-ups. Large firms commercialize the inventions that they generate internally; however, if they fail to innovate, they can collaborate with start-ups and commercialize their inventions. Thus, markets for technology reduce the large firms' incentives to invest in internal research by giving them an "outside option" - external (start-up) inventions. Universities perform a dual role in our model: (i) they train scientists that large firms can hire (thus reducing the cost of internal research) and (ii) they employ researchers who may start their own businesses (thus increasing the number and quality of external inventions). 
We explore the possibility that the rise and fall of corporate internal research documented in the previous section may be related to the growth of American universities. Specifically, we argue that the growing availability of qualified scientists may have initially encouraged large corporations to create their own labs to compensate for a paucity of external sources of invention. However, as universities grew larger and larger, corporations started to increasingly rely upon universities and university start-ups to produce more of the inventions they needed. ${ }^{4}$

\section{$3.1 \quad$ Set-up}

The model has two periods. In the first period, a large firm invests in internal research. Let $p$ be the probability that the investment generates a useful invention. The value of this internal invention is $V_{I}$. The cost of internal research associated with a probability of invention $p$, is $\frac{1}{2} c p^{2} .{ }^{5}$ Thus, the payoff from internal research ${ }^{6}$ is:

$$
p V_{I}-\frac{1}{2} c p^{2}
$$

With probability $1-p$, however, internal research fails to produce an invention. In the second period the firm will then search for an external invention. Thus we assume that commercializing an internal invention and commercializing an external invention are mutually exclusive. That is, the large firm cannot pursue both, perhaps due to limits to managerial attention, or financial constraints. Thus, from the point of view of the large firm, internal and external inventions are substitutes. ${ }^{7}$

\footnotetext{
${ }^{4}$ Our model highlights the effects of university research and education on corporate R\&D. However, reversing the usual conception of industry building on 'abstract' science, it must also be recognized that in many instances scientific "understanding followed practice" (Rosenberg and Birdzell, 1986: 247). Many sciences, such as chemistry, electric engineering, and genetics have developed as an effort to understand and improve upon current industrial practices, and to solve practical problems. Corporate sponsorship of university research is also important in many scientific fields. A more complete model of science and corporate R\&D would also incorporate linkages from corporate R\&D to university science.

${ }^{5}$ Notice that we are not assuming that inventions necessarily arise from research, merely that a certain amount of research is needed for successful invention. A serenditpitous invention may spur research for the additional improvements required for commercial success.

${ }^{6}$ We could equivalently write this problem in terms of the number of scientists $x$ employed in a corporate lab. For instance, we could assume that $p(x)=\alpha \sqrt[2]{x}$ is the probability that a lab employing $x$ scientists will make a scientific discovery. Then $\frac{1}{2} c[p(x)]^{2}=\frac{1}{2} c \alpha^{2} x$, where $w \equiv \frac{1}{2} c \alpha^{2}$ is a scientist's wage.

${ }^{7}$ That internal and external inventions are mutually exclusive is a simplification. We could construct a model where large firms do internal research and also engage in some collaboration. What is important is that there is some substitution at the margin between internal and external inventions. If instead the large firm could commercialize an unlimited number of internal and external inventions simultaneously, the trade off between internal and external inventions emphasized in this model would not be present.
} 
There are two start-ups that can generate external inventions. We assume that (i) these inventions compete for the same market of value $V_{E}$ (i.e., start-up inventions are substitutes in the marketplace) and (ii) invention probabilities are independent across start-ups. These assumptions imply that, while the two start-ups are trying to solve the same problem (because of assumption (i)), they do so by adopting different technological or commercial approaches (because of assumption (ii)). Thus, it is possible that one start-up succeeds at developing an invention, while the other fails. For instance, consider the problem of miniaturizing microchips in semiconductors. Historically, some firms tried to solve this problem by miniaturizing components, while others tried to solve the problem by developing an integrated circuit (Cohen and Malerba, 2001). Texas Instruments build the first working example of integrated circuit in 1958 using germanium; Fairchild Semiconductor followed 6 months later with a new, more practical version using silicon. The integrated circuit made of silicon eventually came to dominate the market, while the other approaches were largely abandoned. ${ }^{8}$

We also stress that, while start-ups try to solve the same problem, the large firm and the start-ups focus on different problems. The market for the internal invention (worth $V_{I}$ ) and the market for start-up inventions (worth $V_{E}$ ) are distinct. Thus, large firms and start-ups, perhaps because they differ in resources or incentives, tend to specialize on different types of problems and inventions.

As a consequence, there are two types of diversity in this model: diversity in types of inventions and diversity in approaches to solve the same problem. Both are valuable. Diversity in types of innovations allows for experimentation with different types of problems (both $V_{I}$ and $V_{E}$ can be created). Diversity in approaches allows for experimentation with different methods to solve a given problem (and therefore the probability that value $V_{E}$ is created increases).

Let $q \in(0,1)$ be the probability that a start-up produces an invention in a baseline scenario where collaboration with the large firm is ignored. Because invention probabilities are independent, both start-ups produce an invention with probability $q^{2}$; in that case, we assume that the market $V_{E}$ is shared equally between the start-ups. With probability $2 q(1-q)$, however, only one start-up invents and captures the whole market. Finally, with probability

\footnotetext{
${ }^{8}$ The model captures diversity in approaches by assuming that the probabilities of invention are not perfectly correlated across start-ups (for simplicity, independent). In this model, however, there are only two start-ups. For a given level of correlation, diversity in approaches can also be increased by increasing the number of start-ups.
} 
$(1-q)^{2}$, no invention is produced and value $V_{E}$ is not created. ${ }^{9}$

If internal research fails, the large firm can collaborate with one of the two start-ups to produce an invention and commercialize it. This collaborating start-up may be a local start-up with previous ties to the large firm. Collaboration brings two advantages to the partnering firms, relative to the baseline scenario. First, the probability of invention increases from $q$ to $q+\psi$, where $\psi \in[0,1-q]$ measures the large firm's co-development capabilities. Second, if both start-ups produce an invention, the share of the market that is won by the partnership becomes $(1+\theta) / 2$, where $\theta \in[0,1]$ is a proxy for the value of the large firm's complementary assets. Examples of such complementary assets could be brand recognition, sophisticated advertising campaigns, and increased prominence in distribution channels.

The critical difference between $\psi$ and $\theta$ is that, while an increase in the probability of invention $\psi$ creates social value, the parameter $\theta$ represents a purely re-distributive shift. Collaboration creates social value because of the added chance $\psi(1-q)$ that a start-up creates value $V_{E}$. By contrast, $\theta$ only measures how value $V_{E}$ is distributed between the partnering firms and the non-collaborating start-up. In the following, we will sometimes call the benefits associated with $\psi$ the "value-creating advantage" of collaboration, and the benefits associated with $\theta$ the "appropriability advantage".

Given these assumptions, the value that accrues to the large firm and the start-up if they form a partnership is:

$$
(q+\psi)\left[(1-q)+\frac{1+\theta}{2} q\right] V_{E} .
$$

Let $\lambda$ be the share of this value goes to the large firm, and $1-\lambda$ the share that goes to the start-up. Remember that the large firm only collaborates with the start-up if internal research fails (which occurs with probability $1-p$ ) Thus, assuming that the large firm and the start-up agree to collaborate, the total payoff that accrues to the large firm is

$$
\Pi(p)=p V_{I}-\frac{1}{2} c p^{2}+(1-p)(q+\psi)\left[(1-q)+\frac{1+\theta}{2} q\right] \lambda V_{E}
$$

while the payoff that accrues to the collaborating start-up is

$$
\pi_{C}=p q\left[(1-q)+\frac{1}{2} q\right] V_{E}+(1-p)(q+\psi)\left[(1-q)+\frac{1+\theta}{2} q\right](1-\lambda) V_{E} .
$$

\footnotetext{
${ }^{9}$ Section 3.2 formalizes the idea that start-up invention $q$ is spurred by university research $r$. In addition, start-ups must also typically perform some $\mathrm{R} \& \mathrm{D}$ to invent (otherwise, the probability of invention $q$ would presumably be 0 ). The current model abstracts from start-ups' investments in R\&D. However, these costs could easily be incorporated in the model without qualitatively affecting the results.
} 
Note that the large firm will agree to collaborate if $\lambda \geq 0$, whereas the start-up will agree to collaborate if

$$
(q+\psi)\left[(1-q)+\frac{1+\theta}{2} q\right](1-\lambda) \geq q\left[(1-q)+\frac{1}{2} q\right] .
$$

Define $\bar{\lambda}$ as the value of $\lambda$ such that (4) holds with equality. Cleary $\bar{\lambda}$ increases in $\psi$ and $\theta$, the value-creating and appropriability advantages of collaboration. Collaboration is beneficial to both partners and hence possible only if $\lambda \in[0, \bar{\lambda}]$. Within this range, we can think of $\lambda$ as reflecting the relative bargaining power of the large firm, vis-à-vis the start-up.

The large firm chooses the optimal level of internal research effort $p$ that maximizes its expected payoff (2). Assuming an interior solution and setting $k=\frac{V_{E}}{V_{I}}$, this yields:

$$
p^{m}=\frac{V_{I}}{c}\left[1-(q+\psi)\left((1-q)+\frac{1+\theta}{2} q\right) \lambda k\right] .
$$

Several factors affect investment in internal invention: the value of internal innovation $V_{I}$, the cost of internal research $c$, the probability of external invention $q$, the share of the value of external invention captured by the large firm $\lambda$, the relative value of external invention $k$, and $\psi$ and $\theta$, the value-creating and appropriability advantages of collaboration.

\subsection{Growth of American universities and investments in internal research}

We can use this simple model to examine how the growth of American universities has affected the incentives to invest in internal research. Let $r \in[0,1]$ be an index parametrizing the 'size' and 'quality' of American universities. Clearly $r$ has grown substantially over the last century and a half.

Universities perform a dual role in our model. First, they train scientists that large firms can hire. This reduces the cost, $c$, of carrying out internal research. Formally, we assume $c$ is a (weakly) decreasing function of $r$. A reduction in $c$ unambiguously raises internal research: $p^{m}$ will increase as $c$ falls.

Second, universities employ scientists who may generate inventions and start their own businesses. Thus, the probability of start-up invention $q$ is a (weakly) increasing function of $r$. The effect of an increase in external invention $q$ on $p^{m}$ is not obvious. There are two countervailing forces, which we label the 'matching' and the 'competition' effects. On the one hand, when there are more start-ups, the large firm is more likely to find a partner to commercialize an external invention (the term $(q+\psi)$ in $(5)$ increases). This implies that $p^{m}$ 
tends to decline, because technology markets provide a better alternative to internal research. On the other hand, more start-ups also mean more competition for the large firm and its partner (the term $(1-q)+q(1+\theta) / 2$ in equation (5) decreases). This competition effect reduces the benefits of collaboration and increases the incentives to invest in internal research $p^{m}$.

Our brief historical review showed that internal research was initially low, increased over time along with an increase in the size and quality of universities, and then started to decline. These trends were mirrored by an initial reliance upon external innovation, followed by a focus on internal innovation, and subsequently followed by a renewed openness to external innovation. In terms of the model, this suggests that as $r$ grew larger over time, $p^{m}$ first increased and then declined.

We can rewrite (5) as

$$
p^{m}(r)=f(r) g(r)
$$

where

$$
f(r)=\frac{V_{I}}{c(r)} \text { and } g(r)=\left[1-(q(r)+\psi)\left((1-q(r))+\frac{1+\theta}{2} q(r)\right) \lambda k\right] .
$$

Appendix 1 provides conditions under which $p^{m}$ first increases and then declines with $r$. Intuitively, these conditions say that, when $r$ is low, $f(r)$ grows rapidly compared to the decline in $g(r)$ as $r$ increases, but when $r$ is very large, $g(r)$ declines relatively rapidly. These conditions are more likely to hold when $c$ and $q$ are "sufficiently" convex in $r$. This implies that, when American universities were small ( $r$ low), growing investment in universities must have greatly reduced the cost $c$ of hiring scientists. However, later on, when American universities were already training large numbers of researchers ( $r$ big), this effect was much smaller. Conversely, at first start-up invention $q$ must not have been greatly affected by growing investment in universities. However, later on, when American universities became among the best in the world ( $r$ big), additional investment in universities began to spur significant start-up activity.

As a numerical example, suppose $c(r)=1-\frac{1}{2} \sqrt{r}, q(r)=\frac{1}{2} r, V_{I}=1$ and $\lambda k=\frac{1}{2}$. Figures $6 \mathrm{a}-6 \mathrm{~d}$ plot $p^{m}(r)$ for different values of $\psi$ and $\theta \cdot{ }^{10}$ In all cases, $p^{m}(r)$ first increases and then declines with $r$.

\footnotetext{
${ }^{10}$ Note that the start-up will agree to collaborate only if condition (4) holds. Except when $\psi=\theta=0$, we can always choose $\lambda$ and $k$ so that $\lambda k=\frac{1}{2}$ and condition (4) holds.
} 


\section{Figures 6a-6d}

Because internal invention and collaboration are substitutes in our model, the same conditions imply a U-shaped pattern in the importance of technology markets as $r$ increases. That is, the probability of collaboration $1-p$ first decreases and then increases with $r$.

While our discussion emphasizes the role of American universities, this was of course not the only factor that affected investments in internal research. In discussing why around the 1920's in-house corporate labs supplanted the individual inventor, Lamoreaux and Sokoloff (1999) stress the emergence of large firms with significant market power. In our model, this can be captured by an increase in $V_{I}$ (keeping $k$ constant). This would increase $p^{m}$, precisely as Lamoreaux and Sokoloff suggest. Similarly, Hounshell (1996) argues that antitrust pressures (at least until Reagan's antitrust revolution in the 1980's) reduced large firms' ability to rely on M\&A as a source of growth. This encouraged firms to seek alternative sources of growth, especially innovation. Initially, this meant internal invention. Over time, however, the growth in the the number of producers seeking innovations encouraged the entry of specialized technology suppliers by broadening the pool of potential buyers of technology (Bresnahan and Gambardella, 1998). Thus, especially after the 1980's, we would expect internal research to decline because technology markets provide an increasingly better alternative to the big corporate lab.

\subsection{Diversity and social welfare}

Next, we compare the outcome of our market economy with the outcome that would be selected by a planner trying to maximize social welfare. Throughout, we will assume that the firms' private value of the invention is also the social value; that is, we ignore information spillovers and consumer surplus. This extreme assumption eliminates a typical source of market inefficiency, namely underinvestment in R\&D due to imperfect appropriability of the returns from innovation. Nevertheless, as we will see, inefficiencies remain.

In our model, large firms can either under-invest or over-invest in internal research, depending on parameter values. Thus, our underinvestment problem would be exacerbated if there was also the traditional imperfect appropriability problem, whereas our overinvestment problem would be mitigated. 
We begin by computing the probability $P_{\text {ext }}$ that at least one external invention is produced:

$$
P_{\text {ext }}(p)=\left(1-(1-q)^{2}\right)+(1-p) \psi(1-q)
$$

The first term is the baseline probability that, without the support of the large firm, at least one start-up will produce an invention. The second term captures the contribution of the large firm to external invention. $P_{\text {ext }}$ decreases with $p$ because, if internal research succeeds, the large firm will not collaborate. Hence the co-development benefits of collaboration $\psi$ will not accrue.

Social welfare $S W$ is the sum of the surplus from internal invention, $p V_{I}-\frac{1}{2} c p^{2}$, and the surplus arising from external invention, $P_{\text {ext }}(p) V_{E}$ :

$$
\begin{aligned}
S W(p) & =p V_{I}-\frac{1}{2} c p^{2}+P_{e x t}(p) V_{E} \\
& =p V_{I}-\frac{1}{2} c p^{2}+(1-p) \psi(1-q) V_{E}+\left(1-(1-q)^{2}\right) V_{E} .
\end{aligned}
$$

Note that society only cares that one start-up invention is brought to market - if both startups succeed, the social value of the second innovation is zero. This is because start-ups experiment with different ways of solving the same problem.

Maximizing social welfare (7) with respect to $p$ yields

$$
p^{s}=\frac{V_{I}}{c}[1-\psi(1-q) k]
$$

where $k=\frac{V_{E}}{V_{I}}$ is the relative importance of the external invention.

Inspection of (7) reveals that, in choosing $p^{s}$, the social planner trades off the benefits from two types of diversity: diversity in types of inventions and diversity in approaches. By increasing $p$, the social planner increases the chance that a type of invention different from start-up invention - the large lab's invention - is produced. Both $V_{I}$ and $V_{E}$ can be created. However, a larger $p$ reduces the probability of collaboration. Collaboration, however, only adds social value when the other non-collaborating start-up fails (which occurs with probability $1-q$ ). Indeed, insofar start-ups only differ in the approaches for solving the same problem, their efforts are substitutes from society's viewpoint. Collaboration is socially valuable because it encourages multiple, not perfectly correlated (and hence diverse) approaches to start-up invention.

From society's viewpoint, therefore, investment in internal research is beneficial because it promotes diversity in the types of problems that firms try to solve; collaboration instead 
facilitates multiple start-up inventions and hence promotes diversity in the approaches used to try to solve similar problems.

Let

$$
P_{\text {ext }}^{m}=P_{\text {ext }}\left(p^{m}\right)
$$

be the probability that at least one external invention is produced when $p$ is chosen optimally by the large firm. Similarly, let

$$
P_{e x t}^{s}=P_{e x t}\left(p^{s}\right)
$$

be the probability that at least one external invention is produced when $p$ is chosen to maximize social welfare. Note that since $P_{e x t}$ is decreasing in $p, P_{e x t}^{s}<P_{e x t}^{m}$ if $p^{s}>p^{m}$, and $P_{e x t}^{s}>P_{e x t}^{m}$ if $p^{s}<p^{m}$. Underinvestment in internal research and excessive tendency to engage in open innovation are closely intertwined. Indeed, if the external research sector did not exist, the private and social value of internal research would coincide and would both be given by (1). Thus, underinvestment in internal research is caused by an excessive incentive (from society's standpoint) to engage in open innovation, and conversely for overinvestment in internal research.

Proposition 1 compares the market outcome $\left(p^{m}, P_{e x t}^{m}\right)$ to the socially efficient outcome $\left(p^{s}, P_{e x t}^{s}\right)$ and provides a simple condition characterizing the types of inefficiencies that can occur.

Proposition 1 (Diversity). Let $\lambda \in[0, \bar{\lambda}]$. The large firms under-invests in internal research $\left(p^{s}>p^{m}\right)$ and engages excessively in open innovation $\left(P_{\text {ext }}^{s}<P_{\text {ext }}^{m}\right)$ if

$$
\lambda\left(1+\frac{1+\theta}{2} \frac{q}{1-q}\right)>\frac{\psi}{q+\psi} .
$$

If this inequality is reversed, the large firms over-invests in internal research $\left(p^{s}<p^{m}\right)$ and engages too little in open innovation $\left(P_{\text {ext }}^{s}>P_{\text {ext }}^{m}\right)$.

Proof. $p^{s}>p^{m}$ implies $(q+\psi)\left[(1-q)+\frac{1+\theta}{2} q\right] \lambda>\psi(1-q)$. After some manipulations, this yields condition (9).

Proposition 1 shows that underinvestment in internal research and socially excessive open innovation are more likely to occur when $q, \theta$ and $\lambda$ are large and $\psi$ is small. Conversely, overinvestment in internal research and too little open innovation are more likely when $q, \theta$ and $\lambda$ are small and $\psi$ is large. 
Two effects drive these results. The first is rent sharing. Because the large firm and the start-up share the rents from successful innovation, the large firm tends to have socially insufficient incentives to collaborate. The larger $\lambda$ (the share of the rents that goes to the large firm), the greater the large firm's incentives to engage in open innovation, and hence the lower its incentives to invest in internal research.

The second effect relates to competition and appropriability. Even when the other start-up innovates, the large firm still reaps some profit from an open innovation strategy because the start-up market $V_{E}$ is shared among the competing inventions. This component of the large firm's profit is not included in the social welfare because society does not care about who wins the market $V_{E}$; society only cares that at least one invention is brought to market (Dasgupta and Maskin, 1987). The better the partnership is at winning market share at the expense of the independent start-up (as captured by the parameter $\theta$ ), the greater the incentives of the large firm to engage in open innovation. If $\theta$ is large enough, this competitive, 'me too' incentive can more than compensate for the opposite, rent sharing effect. The large firm will tend to excessively engage in open innovation, and will underinvest in internal research.

It is important to emphasize that, while open innovation may generate too many 'me too' inventions, this strategy is in general not without social value. Start-ups, even if they are trying to solve similar problems, attempt different approaches to invention. This diversity in approaches benefits society. In choosing the socially optimum level of internal research $p^{s}$, the planner effectively trades off the benefits from heterogeneity in types of inventions (internal vs. start-up innovation) with the benefits from heterogeneity in approaches (ensuring that at least one start-up innovation is created). Indeed, in our model the market can exhibit either too much or too little open innovation, depending on parameter values. ${ }^{11}$

The model emphasizes how the growth of American universities may have affected the evolution of the American innovation ecosystem. We assumed that, as universities $r$ grow, large labs' staffing costs $c$ decline and the probability of start-up invention $q$ increases. Inspection of (9) immediately yields the following result.

Corollary. As r grows, it becomes more likely that the large firm will under-invest in internal research $\left(p^{s}>p^{m}\right)$ and will excessively engage in open innovation $\left(P_{\text {ext }}^{s}<P_{\text {ext }}^{m}\right)$.

\footnotetext{
${ }^{11}$ Open innovation is also socially beneficial because the large firm has co-development capabilities $\psi$. The greater $\psi$, the greater the social benefits from open innovation. Because these benefits are not fully captured by the large firm (due to rent sharing), the large firm is more likely to over-invest in internal research and engage too little in open innovation when $\psi$ is large.
} 
Intuitively, underinvestment in internal research is more likely when start-up innovation is abundant $(q(r)$ large), because then the risk of 'me too' inventions is more serious. Large firms would generate more social welfare if they devoted some of their resources to internal research, instead of trying to acquire inventions in the market.

Equation (9) characterizes the sign (or direction) of the inefficiency - whether we have underinvestment or overinvestment in internal research. We can also examine how changes in $r$ affect the size of the inefficiency. The size of the inefficiency is given by

$$
p^{s}-p^{m}=\frac{V_{E}}{c}\left[\lambda\left(1+\frac{1+\theta}{2} \frac{q}{1-q}\right)-\frac{\psi}{q+\psi}\right] .
$$

There is an interesting asymmetry in how $r$ affects $p^{s}-p^{m}$. When $r$ is large, underinvestment in internal research $\left(p^{s}>p^{m}\right)$ is more likely because a bigger $q$ tends to make the term in square brackets positive. In addition, a large $r$ also lowers $c$, the cost of staffing a lab. This magnifies the size of the inefficiency, because the term $V_{E} / c$ in (10) becomes bigger. By contrast, when $r$ is small, the term in square brackets is negative and overinvestment in internal research occurs. Nevertheless, the size of the inefficiency $p^{s}-p^{m}$ may remain small (in absolute value) because, when $r$ is small, $c$ tends to be large. This asymmetry suggests that the problem of underinvestment in internal research that occurs when universities $r$ spur a lot of start-up activity may be more severe than the problem of overinvestment in internal research that occurs when universities are small. ${ }^{12}$

\section{The benefits of diversity}

Recent evidence indicates that, in the last few decades, large corporations have withdrawn from internal research. From this fact alone, one cannot conclude that American innovation is at risk. An ecosystem where research is mostly performed by universities and start-ups may be nimbler and more efficient than one where large corporations and their labs play a more important role.

Nevertheless, the opposite view that changes in an innovation ecosystem are always beneficial is also simplistic. As the model above shows, the incentives of large firms to engage in collaboration and open innovation can be excessive from society's standpoint. This problem is most likely to be severe when universities create a vibrant start-up ecosystem where

\footnotetext{
${ }^{12}$ This intuition is reinforced by other considerations. For instance, when consumer surplus is added to the analysis, underinvestment in internal research also becomes a more serious problem.
} 
start-up innovation is plentiful. In that case, the open innovation strategy of large firms can result in 'me too' innovations that the market would have generated anyway. Society would benefit if large firms invested more of their resources in internal research.

The welfare analysis in the model is predicated on the assumption that large firms in their labs produce inventions that are qualitatively different from those produced by universities and smaller firms. In that case, the demise of the large corporate lab can reduce social welfare by reducing diversity in the types of inventions produced. There are several reasons why large firms may focus on inventions that are different from those created by other types of organizations.

First, large firms' research may differ from small firms' research because large firms have access to greater financial resources and can tackle multidisciplinary problems by integrating multiple knowledge streams and capabilities (Tether, 1998; Pisano, 2010). In the semiconductor industry, for instance, Kapoor (2013) finds that integrated incumbents adapted to increasing vertical disintegration by reconfiguring their activities more towards systemic innovations (which require extensive coordination and communication across different stages of production and actors) and less towards autonomous innovations (which require relatively little adjustment). Similarly, Lecuona (2017) finds that large firms were more likely to leverage general purpose technologies to introduce architectural innovations in mobile telephony handsets.

Large firms may also benefit from closer coordination between R\&D and manufacturing. According to Holbrook et al. (2000: 1030), "cross-functional coordination not only contributed to [semiconductor firm] Fairchild's great early commercial success, but it also led to Fairchild's two major breakthroughs: the planar process and integrated circuits". Fabless firms specializing on the design of innovative integrated circuits, while avoiding the high costs of building and operating manufacturing facilities, may find it hard to come up with this type of innovations.

An advantage of large corporate labs is that they can organize their research by problem, rather than by discipline, the approach generally taken by universities. Germany's slow entry to the biotechnology sector, for example, has been partly attributed to the rigidity of German university departments (Rosenberg, 1991). Furthermore, commercialization of university research may be subject to 'frictions', such as geographical isolation from the relevant industry actors (Belenzon and Schankerman, 2013; Bikard and Marx, 2015). This 
may hinder or delay technology transfer from universities to industry. Consistent with this, as Bikard (2015) finds, and Arora et al. (2017) confirm, industry research is more readily used by industry inventors than university research.

While our model emphasizes that the demise of the large corporate lab can be detrimental to society because large and small firms focus on different types of innovations, in reality the demise of the large corporate lab can be a problem for society also because their research activities produce significant external benefits. Xerox has been widely criticized for failing to appropriate the returns of innovations such as the first personal computer with a graphical user interface. Yet, these innovations paved the way for the rise of other American technology giants, such as Apple and Microsoft.

The Xerox case also points to an additional class of external benefits that may arise from the activities of large labs: spin-off activity. Agrawal et al. (2014) find a large innovation premium in regions where numerous small labs coexist with at least one large lab, compared to regions of a similar size without many small labs or a large lab. One important reason appears to be the spin-off activity of large labs, which suggests the presence of significant positive externalities generated by the research activities of large firms. Thus, the best innovation ecosystems may be those where large and small firms coexist.

Steven Klepper (2016) has systematically documented the importance of spin-offs in the US innovation ecosystem. He found that in many high-tech industries, including the early automobile industry, semiconductors and lasers, the leading firms spawned more and better spin-offs. For instance, between 1895 and 1966, spin-offs accounted for 20\% of all the entrants in the automobile industry (145 of 725), but 67\% (14 of 21) of the later industry leaders. In semiconductors, spin-offs by a single early leader, Fairchild Semiconductor, arguably led to the creation of one of the industrial wonders of the modern world-Silicon Valley. The comparison between Fairchild and Texas Instruments is revealing. Texas Instruments was much better managed than Fairchild but also spawned far fewer spin-offs. This suggests the paradoxical conclusion that incompetence in managing a leading firm may be, for society at least, a blessing in disguise. It is likely, in fact, that the spin-offs resulting from the mismanagement of people and research at Fairchild encouraged diversity and innovation far more than the efforts of a well-run Fairchild could have. Consistent with this view, Chesbrough (2002, 2003) finds that stronger links between Xerox and the spin-offs it generated tended to inhibit spin-off performance. The key problem was not Xerox's initial equity position 
in the spin-offs per se, but Xerox's practices in managing the spin-offs, which discouraged experimentation by forcing them to look for applications close to Xerox's existing businesses.

\section{Conclusion}

As documented here and in related work, large US firms are investing less in scientific research and focusing more on development. Small firms also do not appear to make up for a significant portion of the research shortfall. This evidence is consistent with a division of innovative labor where universities specialize in research, small start-ups convert promising new findings into inventions and larger, more established firms specialize in product development and commercialization.

While this increasingly compartmentalized division of innovative labor may be efficient, in this paper we strike a more cautionary note. Using a simple model, we show that, even in the absence of appropriability problems, profit-maximizing firms may under-invest in internal research. In our model, large and small firms focus on solving different problems. Large firms, for instance, may have an advantage at producing innovations that are more complex or costly than those produced by smaller firms or universities. Large firms can use their assets either to commercialize their internal inventions, or to commercialize external inventions acquired from small firms. We show that, although there are benefits in duplicating small firms' research efforts (as any one small firm can fail), sometimes large firms have an excessive incentive to engage in an 'open innovation' strategy. The reason is that large firms may win market share, even when these markets are already populated by other firms trying to commercialize similar inventions. Society, on the other hand, would benefit from greater investment in internal research, as this would result in greater diversity of innovations. Thus, the risk we highlight is that open innovation may tend to crowd out more costly or architectural types of research done in large corporate labs.

In addition, of course, large firms' research efforts may be plagued by appropriability problems. Research is an activity that is well-known to produce important spillovers. Increasing competition, by exacerbating appropriability problems, may reduce the private incentives to invest in internal research, even if its value to society is large.

Rosenberg suggested that diversity in organizational forms is conducive to technological and economic growth. He argued that capitalist economies encourage experimentation by large and small firms, whereas planned, centralized economies put excessive faith on the 
importance of large size (Rosenberg, 1992). In recent times, one key component of the US innovation ecosystem - the large corporate lab - has diminished in importance. This decrease in diversity may be a reason for concern.

\section{References}

[1] Agrawal A, Cockburn I, Galasso A, Oettl A. 2014. Why are some regions more innovative than others? The role of small firms in the presence of large labs. Journal of Urban Economics 81: 149-165.

[2] Arora A, Belenzon S, Patacconi A. 2018. The decline of science in corporate R\&D. Strategic Management Journal 39(1): 3-32.

[3] Arora A, Belenzon S, Sheer L. 2017. Back to Basics: Why do Firms Invest in Research? NBER Working Paper No. 23187.

[4] Arora A, Cohen WM, Walsh JP. 2016. The acquisition and commercialization of invention in American manufacturing: incidence and impact. Research Policy 45(6): 11131128.

[5] Arora A, Fosfuri A, Gambardella A. 2001. Markets for Technology: Economics of Innovation and Corporate Strategy. MIT Press: Cambridge, MA.

[6] Belenzon S, Schankerman M. 2013. Spreading the word: Geography, policy, and knowledge spillovers. Review of Economics and Statistics, 95(3): 884-903.

[7] Bikard M, Marx M. 2015. Frictions in the flow of academic knowledge to industry: Evidence from simultaneous discoveries. Working paper, London Business School, London, UK.

[8] Bhaskarabhatla A, Hegde D. 2014. An organizational perspective on patenting and open innovation. Organization Science 25(6): 1744-1763.

[9] Block F, Keller MR. 2009. Where do innovations come from? Transformations in the US economy, 1970-2006. Socio-Economic Review 7(3): 459-483.

[10] Bresnahan TF. Gambardella A. 1998. The division of inventive labor and the extent of the market. In General Purpose Technologies and Economic Growth, E. Helpman (ed). MIT Press: Cambridge, MA: 253-281.

[11] Bruce R. 1987. The Launching of Modern American Science, 1846- 1876. Alfred A. Knopf: New York. 
[12] Carlson BW. 2013. Innovation and the modern corporation. From heroic invention to industrial science. In Companion Encyclopedia of Science in the Twentieth Century, Krige J, Pestre D (eds). Routledge: New York, NY: 203-226.

[13] Chesbrough H. 2002. Graceful exits and missed opportunities: Xerox's management of its technology. Business History Review 76(4): 803-837.

[14] Chesbrough H. 2003. The governance and performance of Xerox's technology spin-off companies. Research Policy 32(3): 403-421.

[15] Cohen WM, Malerba F. 2001. Is the tendency to variation a chief cause of progress? Industrial and Corporate Change 10(3): 587-608.

[16] Coombs R, Georghiou L. 2002. A new "industrial ecology". Science 296(5567): 471-471.

[17] Dasgupta P, Maskin E. 1987. The simple economics of research portfolios. Economic Journal 97(387): 581-595.

[18] Drake N. 2014. Basic science finds corporate refuge. Nature 509: 18-19.

[19] Dushnitsky G, Lenox MJ. 2005. When do firms undertake R\&D by investing in new ventures? Strategic Management Journal 26(10): 947-965.

[20] Eesley CE, Miller WF. 2018. Impact: Stanford University's economic impact via innovation and entrepreneurship. Foundations and Trends in Entrepreneurship 14(2): 130-278.

[21] Geiger RL. 2004. To Advance Knowledge: The Growth of American Research Universities, 1900-1940. Transaction Publishers: New Brunswick, NJ.

[22] Holbrook D, Cohen W, Hounshell D, Klepper S. 2000. The nature, sources, and consequences of firm differences in the early history of the semiconductor industry. Strategic Management Journal 21(10/11): 1017-1041.

[23] Hoskisson RE, Hitt MA, Hill CWL. 1993. Managerial incentives and investment in R\&D in large multiproduct firms. Organization Science 4(2): 325-341.

[24] Hounshell DA. 1996. The evolution of industrial research in the United States. In Engines of Innovation: U.S. Industrial Research at the End of an Era, Rosenbloom RS, Spencer WJ (eds). Harvard Business Review Press: Boston, MA: 13-85.

[25] Hounshell DA, Smith J. 1988. Science and Corporate Strategy: Du Pont RESD, 19021980. New York: Cambridge University Press

[26] Kay N. 1988. The R\&D function: Corporate strategy and structure. In G. Dosi, C. Freeman, R. Nelson, G. Silverberg, C. Soete (Eds.), Technical Change and Economic Theory. Pinter: London. 
[27] Kaplan S, Lerner J. 2010. It ain't broke: The past, present, and future of venture capital. Journal of Applied Corporate Finance 22(2): 36-47.

[28] Kapoor R. 2013. Persistence of integration in the face of specialization: How firms navigated the winds of disintegration and shaped the architecture of the semiconductor industry. Organization Science 24(4): 1195-2013.

[29] Kenney M. 2011. How venture capital became a component of the US National System of Innovation. Industrial and Corporate Change 20(6): 1677-1723.

[30] Klepper, S. (2016). Experimental capitalism: The nanoeconomics of American high-tech industries. Princeton University Press: Princeton NJ.

[31] Kortum S, Lerner J. 2000. Assessing the contribution of venture capital to innovation. Rand Journal of Economics 31: 674-692.

[32] Lamoreaux NR, Sokoloff KL. 1999. Inventors, firms, and the market for technology in the late nineteenth and early twentieth centuries. In Learning by doing in markets, firms, and countries. University of Chicago Press, 19-60.

[33] Lerner J. 2012. The architecture of innovation: The economics of creative organizations. Harvard Business Review Press: Cambridge, MA.

[34] Mazzucato M. 2013. The Entrepreneurial State. Debunking Public vs. Private Sector Myths. Anthem Press: London, UK.

[35] Mowery DC. 1983. Industrial research and firm size, survival, and growth in American manufacturing, 1921-1946: An assessment. Journal of Economic History 43(4): 953980 .

[36] Mowery DC. 1995. The boundaries of the U.S. firm in R\&D. In Coordination and Information: Historical Perspectives on the Organization of Enterprise, Lamoreaux NR, Raff DMG (eds). University of Chicago Press: Chicago: 147-182.

[37] Mowery DC. 2009. Plus ca change: Industrial R\&D in the "third industrial revolution". Industrial and Corporate Change 18(1): 1-50.

[38] Mowery DC. 2010. Military R\&D and innovation. Handbook of the Economics of Innovation 2: 1219-1256.

[39] Mowery DC, Rosenberg N. 1993. National innovation system of the United States. In Nelson RR (ed.) National innovation systems: A comparative study. Oxford, UK: Oxford University Press.

[40] Mowery DC, Rosenberg N. 1998. Paths of innovation: Technological change in 20thcentury America. Cambridge University Press. 
[41] Nelson, R.R. and Rosenberg, N., 1993. Technical innovation and national systems. National innovation systems: A comparative analysis, pp.3-21. In Nelson, R.R. ed., 1993. National innovation systems: a comparative analysis. Oxford University Press.

[42] NSF Science \& Engineering Indicators 2012, Appendix Tables 4-3, 4-8 and 4-9.

[43] NSF Science \& Engineering Indicators 2016, Chapter 5. Academic Research and Development.

[44] Pisano G. 2010. The evolution of science-based business: innovating how we innovate. Industrial and Corporate Change 19(2): 465-482.

[45] Rosenberg N. 1974. Science, invention and economic growth. Economic Journal 84(333): 90-108.

[46] Rosenberg N. 1990. Why do firms do basic research (with their own money)?. Research policy 19(2): 165-174.

[47] Rosenberg N. 1991. Critical issues in science policy research. Science and Public Policy 18(6): 335-346.

[48] Rosenberg N. 1992. Economic experiments. Industrial and Corporate Change 1(1): 181203.

[49] Rosenberg N, Birdzell LE. 1986. How the West grew rich. Mumbai: Popular Prakashan.

[50] Rosenberg N, Nelson RR. 1994. American universities and technical advance in industry. Research Policy 23(3): 323-348.

[51] Rosenberg N, Nelson RR. 1996. The roles of universities in the advance of industrial technology. In Engines of Innovation: U.S. Industrial Research at the End of an Era, Rosenbloom RS, Spencer WJ (eds). Harvard Business Review Press: Boston, MA: 13-85.

[52] Smith DK, Alexander RC. 1988. Fumbling the Future: How Xerox Invented, Then Ignored, the First Personal Computer. William Morrow and Company, New York.

[53] Stokes DE. 1997. Pasteur's Quadrant: Basic Science and Technological Innovation. Brookings Institution Press.

[54] Swann JP. 1988. Academic scientists and the pharmaceutical industry: Cooperative research in twentieth-century America. John Hopkins University Press: Baltimore.

[55] Tether BS. 1998. Small and large firms: sources of unequal innovations? Research Policy 27(7): 725-745. 


\section{Appendix 1: Comparative statics of internal research}

Recall

$$
p^{m}=\frac{V_{I}}{c}\left[1-(q+\psi)\left((1-q)+\frac{1+\theta}{2} q\right) \lambda k\right] .
$$

Let $r \in[\underline{r}, \bar{r}]$ be the 'size' of American universities. Assume $c$ and $q$ are functions of $r$, with $\frac{d c}{d r} \leq 0, \frac{d q}{d r} \geq 0, q(\underline{r})=\underline{q}>0$ and $q(\bar{r})=\bar{q} \leq 1$. Define

$$
\begin{aligned}
& f(r)=\frac{V_{I}}{c(r)} \\
& g(r)=1-(q(r)+\psi)\left((1-q(r))+\frac{1+\theta}{2} q(r)\right) \lambda k .
\end{aligned}
$$

We want to provide conditions under which $p^{m}$ first increases then decreases in $r$. Note

$$
\frac{d^{2} p^{m}}{d r^{2}}=f^{\prime \prime} g+f g^{\prime \prime}+2 f^{\prime} g^{\prime}
$$

where primes denote derivatives with respect to $r$. Because $c$ is (weakly) decreasing in $r$, $f^{\prime} \geq 0$. The sign of $g^{\prime}$ is a priori ambiguous. However, if

$$
2 \theta \geq \psi(1-\theta)
$$

then $g^{\prime} \leq 0$ over the relevant range $q \in(0,1]$. To see this, note that $g(r)$ is convex in $q$ and achieves minimum at $q^{\min }=\frac{1-\frac{\psi}{2}(1-\theta)}{1-\theta}$. Note also that $2 \theta \geq \psi(1-\theta)$ implies that $q^{\min } \geq 1$ and thus that $g(r)$ decreases in $q$ (and hence in $r$ ) over the relevant range. For instance, if $\theta$ is close to 1 , then condition $2 \theta \geq \psi(1-\theta)$ holds and $g(r) \simeq 1-t(q+\psi) \lambda k$ is decreasing in $q$ (and $r$ ).

Because $2 \theta \geq \psi(1-\theta)$ implies that $f^{\prime} g^{\prime} \leq 0,(11)$ is negative if $f$ and $g$ are not "too convex" in $r$. Note that

$$
f^{\prime \prime}=\underbrace{\frac{d^{2} f}{d c^{2}}}_{>0} \underbrace{\left(\frac{d c}{d r}\right)^{2}}_{\geq 0}+\underbrace{\frac{d f}{d c}}_{<0} \frac{d^{2} c}{d r^{2}}
$$

is negative if $c$ is "sufficiently convex". Similarly, let $h=(q+\psi)\left((1-q)+\frac{1+\theta}{2} q\right) \lambda k$. Then

$$
g^{\prime \prime}=-\underbrace{\frac{d^{2} h}{d q^{2}}}_{\leq 0} \underbrace{\left(\frac{d q}{d r}\right)^{2}}_{\geq 0}-\underbrace{\frac{d h}{d q} \frac{d^{2} q}{d r^{2}}}_{>0}
$$

is also negative if $q$ is "sufficiently convex". For instance, if $\theta \simeq 1$, then $\frac{d^{2} h}{d q^{2}} \simeq 0$ and any convex function $q$ would do. 
Thus, to summarize, if $2 \theta \geq \psi(1-\theta)$ and $c$ and $q$ are "sufficiently convex", then (11) is negative. Investment in internal research $p^{m}$ first increases and then declines with $r$. Of course to ensure that $p^{m}$ achieves a maximum within the relevant range $[\underline{r}, \bar{r}]$, we also need to assume that $\left.\frac{d p^{m}}{d r}\right|_{r=\underline{r}}>0$ and $\left.\frac{d p^{m}}{d r}\right|_{r=\bar{r}}<0$.

\section{Appendix 2: Additional results}

Proposition 1 in the main body of the paper shows that underinvestment in internal research is more likely when the benefits of collaboration arise from the appropriability advantage $\theta$, rather than the value-creating advantage $\psi$. Here we show that in the extreme case of pure value-creating advantage of collaboration $(\theta=0)$, underinvestment in internal research always occurs. By contrast, in the extreme case of pure appropriability advantage of collaboration $(\psi=0)$, both underinvestment and overinvestment in internal research can occur.

\section{Proposition 2.}

(i). In the pure value-creating case $(\theta=0)$, there is can be under- or overinvestment in internal research. If the start-up appropriates most of the value of the collaboration $(\lambda \simeq 0)$, then there is overinvestment in internal research. If the large firm appropriates most of the value of the collaboration $\left(\lambda \simeq \bar{\lambda}=\frac{\psi}{q+\psi}\right)$, then there is underinvestment in internal research.

(ii). In the pure appropriability case $(\psi=0)$, there is underinvestment in internal research, unless the start-up appropriates all the value of the collaboration $(\lambda=0)$.

Proof of Proposition 2. (i). Suppose $\theta=0$. From Proposition 1, there is underinvestment in internal research if

$$
\lambda\left[1+\frac{1}{2} \frac{q}{1-q}\right]>\frac{\psi}{q+\psi}
$$

and overinvestment if the inequality is reversed. Using (4), it follows that $\lambda \in\left[0, \frac{\psi}{q+\psi}\right]$. If $\lambda \simeq 0$, then clearly the inequality fails and there is overinvestment. If $\lambda \simeq \frac{\psi}{q+\psi}$, then the inequality holds and there is underinvestment in internal research.

(ii). Suppose $\psi=0$. Then $\lambda\left[1+\frac{1}{2} \frac{q}{1-q}\right]>\frac{\psi}{q+\psi}$ holds and there is overinvestment in internal research unless $\lambda=0$. 